\title{
A Recent update of phase change materials (PCM's) in cooling application
}

\author{
Ahmed H. N. Al-Mudhafar ${ }^{1}$, Ali Lateef Tarish ${ }^{2}$ \\ \{E-mail address: alalahmed@stu.edu.iq ${ }^{1}$, alialali@stu.edu.iq $\left.{ }^{2}\right\}$ \\ Thermal Mechanics Eng. Dept., Eng. Technical College-Basra, Southern Technical University, Basra, \\ Iraq $^{1,2}$
}

\begin{abstract}
The use of indirect evaporative cooling in dry weather conditions to charge phase change materials (PCMs) storage systems can reduce overall energy consumption. Lower thermal conductivity is the main limitation of PCM, so a suitable technique must be used to enhance thermal conductivity.. Studies showed that the selection of PCMs for free cooling applications is critical because it depends on the outside temperature at the charging period. Therefore, the outside temperature should be lower than the solidification temperature of the PCMs during charging, and the melting temperature should be lower than the inside temperature during the discharging process. The objective of this review article is to evaluate current phase change materials applications in cooling systems. The investigations about the application of PCMs in cooling systems undertaken by different researchers will be described in this article. Free cooling and heating system using building envelop, free cooling and heating using Air Handling Unit latent heat thermal storage systems, air conditioning, and refrigeration systems are discussed briefly. About 35\% of these studies used PCMs used in roofs, ceilings, and attics. Moreover, $6 \%$ of studies used PCMs on the floor, so there is a need for future studies about the application of PCMs on the floor to storage energy at off-peak load hours and release it at peak load hours to reduce energy consumption costs. The results in the literature showed that using PV-PCM in the attic can reduce up to 55\% of the attic cooling load. PCMs can store a large amount of coldness during the phase change process which takes place at a constant temperature, so it is appropriate to use in the building.
\end{abstract}

Keywords: PCMs; thermal storage; building envelop; free cooling; air conditioning.

\section{Introduction}

Nearly $40 \%$ of worldwide carbon dioxide emissions and energy consumption result from the urban sector [1]. Most of the energy used is towards cooling and heating, thus reducing such consumption could improve the emissions of greenhouse gases in terms of using phase change materials (PCMs) to store and release thermal energy [2]. PCMs are materials that have strong heat performances and constant temperature [3-4]. As the substance changes its phase from liquid to solid or from solid to liquid thermal energy is released or absorbed [5]. PCMs are capable of storing a large amount of energy, therefore it is appropriate for use in buildings [6]; and improving heat energy storage [7] and their related discharing process using PCMs [8, 9]. The low thermal conductivity is one of the main drawbacks of the PCMs which reduce their heat transfer efficiency [10]. There are many advantages of integrating PCMs in the building that can be found in [11-13]. Cooling systems derived by solar is an attractive technology because of its availability and friendliness to the environment. Cooling produced by solar-driven equipment cannot correspond to the demand because of the periodic nature of solar energy [14]. To increase the efficiency of the system thermal energy storage (cold or hot) system is needed 
to integrate with the solar cooling system $[15,16]$. LHTES is more suitable than sensible energy storage because of the large storage energy densities with a small variation of volume and temperature $[17,18]$.

This paper focuses on latent heat thermal storage systems which are used to store heat or cold in PCMs. The purpose of this article is to review the current application of PCMs in cooling systems. These applications are divided into four groups, namely: free cooling and heating system using building envelope, free cooling and heating using air handling unit based on heat thermal storage, air conditioning, and refrigeration systems.

\section{Free cooling and heating concept with applications}

The operating principle of free cooling using PCMs is by storing heat from the building interior in the day time and then releasing heat in the night as shown in Fig. 1 which takes place at the relatively low-temperature difference. The PCMs solidified the operation process from daytime and night [19]. This process shows its importance in Iraq in which 15 degrees difference could exist $[1,20]$. The next section discusses the applications of PCMs in-wall, roofs, ceilings, attic, and floors.

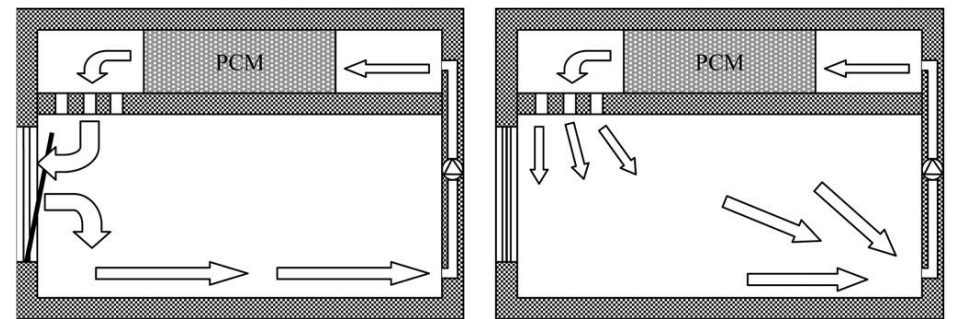

Fig. 1. PCM "free-cooling system": (left) PCM at night, (right) during the day.

\subsection{Application of PCM in walls}

Gracia et al. [21] experimentally tested two similar buildings one only one with ventilated façade to drop the thermal variations to prevent overheating or used to storage free cold at night. To change the operating mode of the façade six automatic opening gates were used. The study highlighted the efficiency of night-free cooling in reducing building cooling load. The system could provide air temperature below the set point temperature during summer conditions. Diarce et al. [22] used Fluent software to develop a 2D CFD model to study ventilated façade containing PCM on its outer surface as represented in Fig. 2. Moreover, a test room was built and integrated with a ventilated façade. The results indicated that for the ventilated façade it was suitable to consider PCM as a solid material with variable specific heat and neglect the effect of its phasechange during solidification and melting. The developed CFD model could be used to model ventilated façade with or without PCM with good accuracy compared to experimental data. 


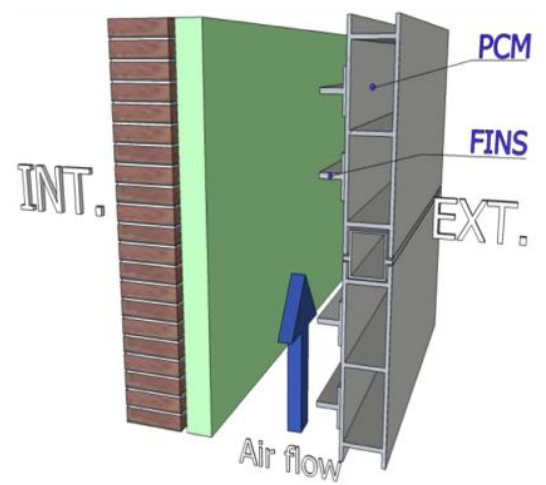

Fig. 2. The developed façade [22].

Building of light weight discussed by Barzin et al. [23] using PCM-impregnated gypsum boards in New Zealand for two tests. Charging coldness by utilizing night ventilation and free cooling enhanced the efficiency of using PCM as a cold storage system. The results showed that $73 \%$ of electricity was saved during one week period by using this method. The study recommended using this method to store cold energy in office buildings by using night ventilation during off-load hours. EnergyPlus software is used by Lei et al. [24] to illustrate the thermal variations in tropical weather (Singapore), in which the results achieved 21-32\% of heat gain. The proper selection process of suitable phase change temperature is critical for PCM. The study highlighted that installing PCM in the exterior surface of exterior walls is preferred in tropical regions compared to interior location because it uses outside free night cold to solidify which lead to a reduction in cooling energy consumption. The results highlighted the advantage of using PCMs in tropical areas compared to other regions because it can reduce the cooling load through building envelop during the whole year, while in other regions PCM is only active in specific seasons. Experimental results by Principi and Fioretti [25] were compared with numerical results and showed similar dynamic performance. Sayyar et al. [26] developed composite nano-PCM and incorporated it into gypsum wallboard by using sandwich construction. The experimental results showed that using nano-PCM wallboard shifts the peak load and reduces the temperature fluctuations inside the room $\left(18.5-26.5^{\circ} \mathrm{C}\right)$ compared to $(13-$ $32{ }^{\circ} \mathrm{C}$ ) for a room that used commercial drywall panels.

Lachheb et al. [27] developed a new gypsum matrix integrated with PCM to improve thermal storage in building materials. The gypsum matrix developed by Lachheb et al. [27] was produced by placing 24 copper tubes inside an aluminum mold (Fig. 3 left), then a pasty mixture of gypsum and water was poured into the mold. The formed composite PCM-gypsum board has $20 * 20 * 1 \mathrm{~cm}^{3}$ dimension as demonstrated in Fig. 3 right. The energy storage performance of the PCM-integrated gypsum board was experimentally evaluated to compare it with conventional gypsum board without PCM by using the transient guarded hot plates method. Moreover, PCM leakage during the liquid state was prevented by using copper tubes. Evola et al. [28] proposed a new methodology to study the effect of using PCM on improving building thermal performance in the summer season. This methodology was based on some statistical indicators which included: frequency of thermal comfort (FTC) and intensity of thermal discomfort (ITD) for occupants. To test this methodology EnergyPlus program was used to simulate the summer thermal performance of using PCM panels in three partitions walls of a central room located in a lightweight office building by using Chambéry (France) weather conditions. The simulation was performed twice for the same building, the first simulation was for building without using 
a PCM panel in its partition and the second was by using PCM on the interior surface of its partition. Simulation results showed that the ITD reduced by about $35 \%$ by using PCM panels with a suitable night ventilation strategy, while the FTC reached $60 \%$ at $(8 \mathrm{ACH})$ compared to $52 \%$ for a case without PCM. Researchers highlighted that the proposed methodology is suitable to help in choosing the suitable PCM depending on thermal comfort requirements and climate conditions. Castell and Farid [29] experimentally validated the previous four indicator methodology used by Evola et al. [28], which tested only for simulation results. The methodology was validated experimentally by incorporating PCM in concrete, timber, and brick. The results showed that the methodology was effective for lightweight buildings without insulation and high heat gain. But it failed for well-insulated massive buildings with low heat gain. The intensity of thermal discomfort (ITD) indicator was found to be the most effective indicator to evaluate the benefits of using PCM compared to other parameters used in the proposed methodology. Additionally, the ITD indicator was modified to take into account a range of temperature levels for thermal comfort depending on the season rather than a single set temperature. The frequency of thermal comfort (FTC) indicator was not suitable for buildings conditioned by the HVAC system, since these systems provide thermal comfort for all hours.

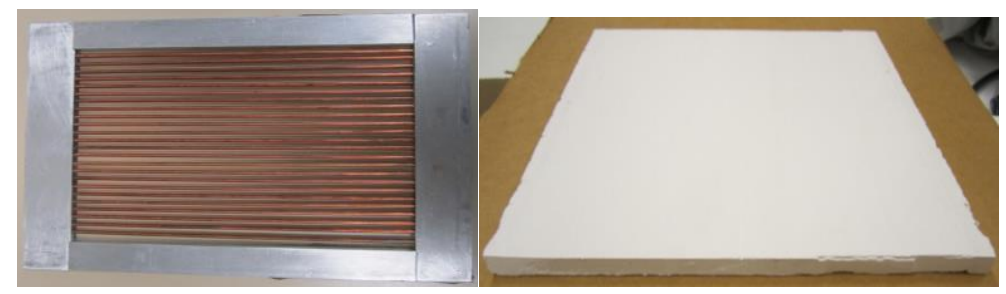

Fig. 3. Copper tubes included inside the mold (left); Copper tubes filled with PCM (paraffin) integrated inside gypsum panel (right).

\subsection{Application of $\mathrm{PCM}$ in roofs, ceiling, and attic}

Thermal stabilities were studied by Chung et al. [30] using different PCM-doped tile roof. Experiments were carried out in artificial summer weather conditions and actual winter conditions in South Korea. The results showed that PCM-doped roof tile can reduce the cooling load in the summer season and also reduce the heating load in winter conditions. Additionally, it reduces the indoor temperature in summer and increases in winter. Dong et al. [31] investigated the same subject but in roofs of residential buildings and compared to others. Many factors, such as roof slope, melting temperature and latent heat of PCM and PCM layer thickness were studied. The results showed that the PCM roof delays the time of peak temperature 3 hours compared to the common roof. By increasing the slope of the roof, the solid fraction of the PCM layer increases, and the heat flux and the average temperature of the roof decrease. The increase in the PCM layer thickness leads to an increase in the delay time of peak temperature. Kos'ny et al. [32] tested the thermal variations of PV-PCM attic and then establish a new control asphalt shingle roof. This roof work as a passive solar collector during winter, where store solar heat during the day and release it during the night. Kos'ny et al. [33] used the ESP-r program to present the effects of attic insulation encompassing and its condensed and dispersed PCM for the residential building located in Arizona, USA. The outcomes of this study showed that the best location of condensed PCM was under the attic floor insulation. Combination of PCM with attic insulation reduce the peak cooling load by more than $25 \%$ and shift it compared to the roof 
without PCM with equivalent R-value. The blends of thermal insulation with PCM showed its potential for thermal energy storage. Simulation results showed that compared to non-PCM insulation the thick layers of PCM-enhanced insulation can produce a passive cooling effect by reversing the direction of heat flow. Kong et al. [34] studied the thermal performance of integrating PCMs in building envelopes. Results showed that the walls can keep the inside room temperature lower than the reference room without utilizing PCM. Zhou et al. [35] numerically simulated using shape-stabilized phase change materials (SSPCM) with 76\% improvement in terms of power consumption with the case without night ventilation and SSPCM. The fan electrical COP for night ventilation increased from 6.5 to 7.5 by using SSPCM. Passive control cooling system for residential buildings was found more effective by Jiao et al. [36] using the Energy Plus program. The computed results in terms of one layer PCM was effective compared to a multi-layer PCM ceiling. Additionally, the phase change temperature of PCMs closer to the monthly average outside air temperature $\left(27^{\circ} \mathrm{C}\right.$ in this case) leads to lower indoor temperature. Moreover, superior heat transfer was achieved by using PCM with high thermal conductivity and low thickness.

\subsection{Application of PCM in floor}

The energy consumption can be reduced using PCM but this relatd heavily on the weather conditions, the position of PCM, the melting point, and the daytime and night temperature. Ceramic tiles were embedded with PCM to enhance building thermal levels by Novais et al. [37]. Test data presented shows a $22 \%$ reduction in temperature and improve thermal performances. The wrong use of PCM could lead to an increase in energy consumption. The use of PCM might decrease the load and leads to reducing the cost of air conditioning devices. The night ventilation enhances the performance of PCM by utilising free cooling from the outside air. The use of PCM integrated with a building envelop outperforms thermal stability during the operations hours in the daytime. This has also confirmed the surface temperature in urban areas can be reduced.

\section{Air Handling Unit latent heat thermal storage systems}

Thermal storage technique can store and release coldness inside indoor environment during day time or used to store hotness at daytime and then released. The electric energy can be reduced in the future building when load demands at the off-peak are conisdered.

\subsection{PCM-cooling storage unit charged by using outside cold at night}

The thermal enactment of a window of an office using a PCM-cooling unit is discussed by Xiang and Zhou [38]. The unit is used to store the free outside cold and release it to the interior during the day. The operation principle of this unit is shown in Fig. 4. The effects showed that the optimum size with night ventilation could decrease inside the room by $3.3{ }^{\circ} \mathrm{C}$ with an 8.7 energy efficiency ratio. Compared to a conventional AC system of similar with the same size, the system could save $1.9 \mathrm{~kW}$ in $1 \mathrm{~h}$ that can be recorded as agood advantage. 


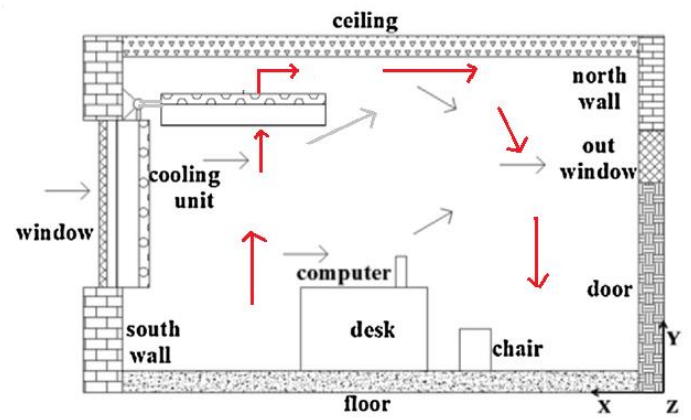

Fig. 4. Cooling unit (grey arrows for air movement and red arrows for air movement in day mode.

The thermal performance of using latent heat thermal storage is investigated by Osterman et al. [39] in an office building. It is observed that high variation of solar heat of about $142 \mathrm{kWh}$ of annual energy consumption could be saved in office buildingstested the thermal performance is studied using multi-PCM by Mosaffa et al. [40-41].. Results showed that decreasing air inlet temperature during the cold charging process increases exergy efficacy. Navarro et al. [42] experimentally studied incorporating PCMs in a new prefabricated concrete slab (active slab) system to use it as a cold storage unit for active cooling. The active slab contains PCM inside its hollows. During the daytime, the cold is released to the interior ambient air by heat exchange with PCM. The results showed that between $15 \%-55 \%$ of cooling energy could be saved by using this technology compared to reference slabs without PCM. Sun et al. [43-45] developed latent heat PCM-cold storage unit to store free cold at night and used it to cool telecommunications-based stations (TBSs). A mathematical model was developed to simulate the application of this system in different weather conditions. Results showed that $50 \%$ of annual cooling energy consumption was reduced in the different climatic regions. Raj and Velraj [45] considered the PCM by applying shell and tube heat. The results showed the module improves the heat transfer $1 \mathrm{~m} / \mathrm{s}$ heat velocity and an increased of $2 \mathrm{~m} / \mathrm{s}$ of the solidification time. Tyagi et al. [46] tested the thermal performance of using PCM thermal energy storage for space cooling or heating of building at the typical climate in India. Calcium chloride hexahydrate was used as a PCM. The results showed that (TMS-I) was more effective for space cooling compared to the (TMS-II), While the (TMS-II) was more effective compared to (TMS-I) for space heating. Hasse et al. [47] studied using an aluminum honeycomb panel filled with PCM in which the the thermal inertia of honeycomb samples filled with PCM was larger compared with water or airfilled samples.

\subsection{PCM cold storage unit charged by using indirect evaporative cooling}

Using a concealed heat thermal energy storage system can decrease cooling energy consumption and restore comfort. However, this system depends on the local weather data and it is preferred to use in locations with high-temperature fluctuations between daytime and night in summer. Jaber and Ajib [48] studied the performance of the cooling scheme using a PCM called indirect evaporative and storage unit (IESU). This system consisted of a heat exchanger filled with PCM and an indirect evaporative cooling system. This unit with optimum size could reduce the cooling energy by $80 \%$ from the conventional AC system. The optimum PCM melting temperature to use in this system for Amman climate was $20^{\circ} \mathrm{C}$. The use of evaporative cooling to charge PCMs cold storage systems can reduce energy consumption, especially in dry 
weather conditions. There is a need to produce a prefabricated cold storage system integrated with PCMs because it is easy to integrate into the building structure. Due to the low energy consumption of PCMs cold storage systems compared to conventional schemes, that is operated by a portable generator. So it can be used in locations that are not served by the electrical network.

\section{Air conditioning and refrigeration systems}

Thermal cold storage systems by using PCMs can be used for storage of cooling for offpeak cycles [49]. This reduces energy consumption and makes the system more energy efficient. This improves the peak cooling load and the ability of the cooling system including cost [50]. They also applied for the storage of cold energy from air conditioning systems when operating from solar energy sources and the stored cooling can be used during sunset.

\subsection{Application of PCM in the freezer and refrigerated vehicle}

Oro' et al. [51] investigated food storage champers using PCM to state the system operation faults. Liu et al. [52, 53] tested a new cooler system using PCM thermal storage unit (PCTSU). Simulation results indicated that temperature or mass flow rate increased linearly with heat transfer fluid leads to a faster melting process of PCM and increases the heat transfer rate. The PCTSU is represented in Fig. 5. The results showed that the cosr reduced by $86.4 \%$ compared to nominal systems.

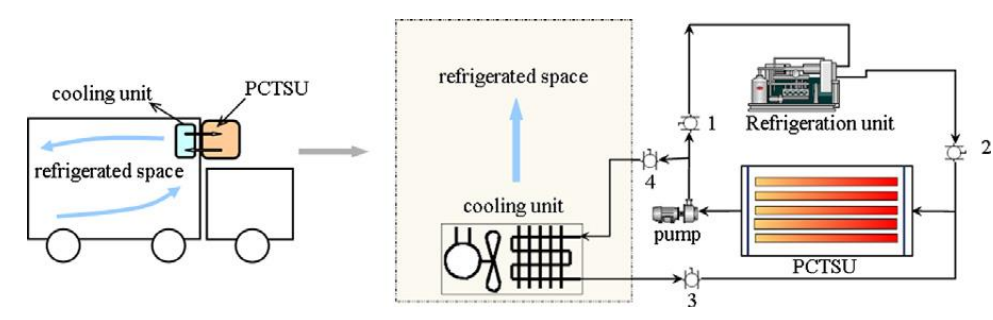

Fig. 5. Proposed refrigeration system [50].

\subsection{Application of PCM store off-peak cooling from cooling systems}

Bruno et al. [54] numerically studied using off-peak PCM-thermal storage and how the heat transfer passed through tubes and the tank. The unit was used to store cold from the chiller at the off-peak cycle. The result stated that $13.5 \%$ of cooling energy was saved with melting temperature of $10{ }^{\circ} \mathrm{C}$. The increasing cold discharging is also found important for load shifting. Li et al. [55] studied the new type of PCM (HS-E2) used in direct contact PCM-cold storage tank to store cold for air conditioning unit. It is observed that charging time and charging capacity increased by decreasing the heat transfer fluid inlet temperature and increasing the PCM flow rate. DSC measurements for this new PCM (HS-E2) showed $173.5 \mathrm{~kJ} / \mathrm{kg}$ latent heat and its solidification temperature was $7.03{ }^{\circ} \mathrm{C}$, so it is suitable to use for thermal storage with conventional AC systems. Experimental data showed a similar trend with numerical results and their variation was about 7\%. Moreno et al. [56] included the heat pump to shift peak cooling load for building by store cold at an off-peak time. The TES tank was used to store cold from the heat pump and use this cold for building cooling. The result showed that PCM storage tank 
supply $14.5 \%$ colder and keep the inside temperature within $20.65 \%$ thermal comfort. The charging time of the PCM tank with 4.55 times the charging time. Chen et al. [57] experimentally investigated using a PCM cold storage tank coupled with an evaporator of an ejector cooling unit. The results showed that the ejector cooling COP was stabilized by using a storage tank. Additionally increasing heat transfer fluid flow rate was led to reducing the effectiveness of charging and discharging. Zhai et al. [58] developed a PCM-cold storage unit by using (lauric and capric acid) PCM with $\left(14.97{ }^{\circ} \mathrm{C}\right.$ ) melting temperature. The PCM testbed operated with a pipe of copper finned with a diameter of $2 \mathrm{~cm}$ surrounded by a cylindrical container with $50 \mathrm{~cm}$ long and $11 \mathrm{~cm}$ diameter. The outcomes showed that the experimental finned unit was reduced by more than $70 \%$. The TC of PCM is powered by using fins and this reduces the phase changes.

\section{Conclusions}

The use of PCMs in building envelopes was more beneficial since heat from the building takes place through the building envelope. The main reason for using PCM in building envelop is its capability to storing heat with fixed temperature. PCMs used in walls, roofs, ceilings, attic, and floor. More than $50 \%$ of these studies used PCMs in walls due to their large surface areas and higher energy consumption in walls. About 35\% of these studies used PCMs in roofs, ceilings, and attics. And 6\% of studies used PCMs on the floor, so there is a need for future studies about the application of PCMs on the floor to store energy at off-peak load hours and release it at peak load hours to reduce energy consumption costs. The thermal performance of PCMs depends on the climatic condition, so PCM should be carefully selected depending on its melting and solidification temperature suitable for local climate conditions. In most of these studies, the cooling energy consumption was reduced and in some of them, the reduction reached $100 \%$. The peak load was reduced by more than $20 \%$. And indoor temperature fluctuation reduced by more than $20 \%$. The application of PCMs in a building depends on weather conditions and in the previous studies presented in this paper about $50 \%$ of these studies were conducted in the USA and European countries and more than $30 \%$ in China. So for future studies, there is a need for more studies in other climate regions like Middle East countries. There are many simulation programs used in the previous studies from this programme: Fluent, Energy-Plus, COMSOL, and ESP-r. Fluent was used for more than $30 \%$ of numerical simulation studies and the Energy-Plus programme used more than $30 \%$ of these studies.

By using PCM as a storage system for free cooling applications in buildings, the outside cold can be stored in the PCM and this cold can be released to the indoor during the hot day hours. This technology can lead to reducing consumption of the energy and the gases emission of greenhouses. But to apply the free cooling technique variation between night and day temperatures must be found. So the free cooling systems depend on the weather data and the melting temperature of the PCM used for storage cooling. For free cooling applications by using building envelop PCMs melting temperature used in the literature range from $\left(16-30{ }^{\circ} \mathrm{C}\right)$. Using PCM to store cooling and heating can lead to reducing the cost of electricity bills by reducing energy consumption in cooling or heating and by shifting the peak load to off-peak hours. Charging the cold storage system which contains PCM during the coldest part of the night can reduce the energy consumption of the system because the cooling system which is used for charging works more efficiently at night. For free cooling applications by using latent heat thermal storage PCMs phase change temperature used in the literature range from $\left(2-15{ }^{\circ} \mathrm{C}\right)$. Using indirect evaporative cooling in dry regions to charge PCMs in cooling can reduce up to 
$80 \%$ of energy consumption compared to the traditional system. The literature showed that using PV-PCM in the attic can reduce up to $55 \%$ of the attic cooling load. PCMs can store of coldness while in teh change process which takes place at un-varied levle of temperature, so it is appropriate to use in the building.

\section{References}

[1] Almudhaffar, Mujtaba, Ali A Monem, and Ahmed H Naseer. "Standardizing the Annual Electric Energy Consumption for a Residential Building in Basrah City." Basrah Journal for Engineering Science 14, no. 2 (2014): 162-175.

[2] Guarino, Francesco, Sonia Longo, Maurizio Cellura, Marina Mistretta, and Vincenzo La Rocca. "Phase change materials applications to optimize cooling performance of buildings in the Mediterranean area: a parametric analysis." Energy Procedia 78 (2015): 1708-1713.

[3] De Gracia, Alvaro, and Luisa F. Cabeza. "Phase change materials and thermal energy storage for buildings." Energy and Buildings 103 (2015): 414-419.

[4] Al-Mudhafar, Ahmed HN, Andrzej F. Nowakowski, and Franck CGA Nicolleau. "Performance enhancement of PCM latent heat thermal energy storage system utilizing a modified webbed tube heat exchanger." Energy Reports 6 (2020): 76-85.

[5] Osterman, Eneja, V. V. Tyagi, Vincenc Butala, N. Abdul Rahim, and Uroš Stritih. "Review of PCM based cooling technologies for buildings." Energy and Buildings 49 (2012): 37-49.

[6] Alizadeh, M., and S. M. Sadrameli. "Development of free cooling based ventilation technology for buildings: Thermal energy storage (TES) unit, performance enhancement techniques and design considerations-A review." Renewable and Sustainable Energy Reviews 58 (2016): 619-645.

[7] Zhou, Dan, G. S. F. Shire, and Yuan Tian. "Parametric analysis of influencing factors in Phase Change Material Wallboard (PCMW)." Applied energy 119 (2014): 33-42.

[8] Abdulrahman, Ruslan, Farah Ibrahim, Ahmed Al-Mudhafar, and Sadoun Dakhil. "Numerical study of PCM melting processes in trapezoidal channel." In Journal of Physics: Conference Series, vol. 1773, no. 1, p. 012017. IOP Publishing, 2021.

[9] Zafar, Sayem, Ibrahim Dincer, and Mohamed Gadalla. "Experimental testing and analysis of R134a clathrates based PCMs for cooling applications." International Journal of Heat and Mass Transfer 91 (2015): 756-765.

[10] Tay, N. H. S., M. Belusko, M. Liu, and F. Bruno. "Investigation of the effect of dynamic melting in a tube-in-tank PCM system using a CFD model." Applied Energy 137 (2015): 738-747.

[11] Zhang, Yinping, Guobing Zhou, Kunping Lin, Qunli Zhang, and Hongfa Di. "Application of latent heat thermal energy storage in buildings: State-of-the-art and outlook." Building and environment 42, no. 6 (2007): 2197-2209.

[12] Kamali, Saeed. "Review of free cooling system using phase change material for building." Energy and Buildings 80 (2014): 131-136.

[13] Tyagi, V. V., D. Buddhi, Richa Kothari, and S. K. Tyagi. "Phase change material (PCM) based thermal management system for cool energy storage application in building: An experimental study." Energy and Buildings 51 (2012): 248-254.

[14] Cheng, Xiwen, Xiaoqiang Zhai, and Ruzhu Wang. "Thermal performance analysis of a packed bed cold storage unit using composite PCM capsules for high temperature solar cooling application." Applied thermal engineering 100 (2016): 247-255.

[15] Diaconu, Bogdan M., Szabolcs Varga, and Armando C. Oliveira. "Numerical simulation of a solarassisted ejector air conditioning system with cold storage." Energy 36, no. 2 (2011): 1280-1291.

[16] Al-Abidi, Abduljalil A., Sohif Bin Mat, K. Sopian, M. Y. Sulaiman, C. H. Lim, and Abdulrahman Th. "Review of thermal energy storage for air conditioning systems." Renewable and Sustainable Energy Reviews 16, no. 8 (2012): 5802-5819. 
[17] Al-Mudhafar, Ahmed HN, Andrzej F. Nowakowski, and Franck CGA Nicolleau. "Thermal performance enhancement of energy storage systems via phase change materials utilising an innovative webbed tube heat exchanger." Energy Procedia 151 (2018): 57-61.

[18] Tarish, Ali Lateef, and Naseer T. Alwan. "Experimental Study of Paraffin Wax-Copper Nanoparticles Thermal Storage Material." International Journal of Modern Studies in Mechanical Engineering 3.3 (2017): 11-17. http://dx.doi.org/10.20431/2454-9711.0303002

[19] Stritih, Uroš, and Vincenc Butala. "RETRACTED: Experimental investigation of energy saving in buildings with PCM cold storage." (2010): 1676-1683.

[20] Tarish, Ali Lateef, Mushtaq Talib Hamzah, and Wasan Assad Jwad. "Thermal and exergy analysis of optimal performance and refrigerant for an air conditioner split unit under different Iraq climatic conditions." Thermal Science and Engineering Progress $19 \quad$ (2020): 100595. https://doi.org/10.1016/j.tsep.2020.100595

[21] De Gracia, Alvaro, Lidia Navarro, Albert Castell, Álvaro Ruiz-Pardo, Servando Álvarez, and Luisa F. Cabeza. "Thermal analysis of a ventilated facade with PCM for cooling applications." Energy and buildings 65 (2013): 508-515.

[22] Diarce, G., Á. Campos-Celador, K. Martin, A. Urresti, A. García-Romero, and J. M. Sala. "A comparative study of the CFD modeling of a ventilated active façade including phase change materials." Applied Energy 126 (2014): 307-317.

[23] Barzin, Reza, John JJ Chen, Brent R. Young, and Mohammed M. Farid. "Application of PCM energy storage in combination with night ventilation for space cooling." Applied Energy 158 (2015): 412-421.

[24] Lei, Jiawei, Jinglei Yang, and En-Hua Yang. "Energy performance of building envelopes integrated with phase change materials for cooling load reduction in tropical Singapore." Applied energy 162 (2016): 207-217.

[25] Principi, Paolo, and Roberto Fioretti. "Thermal analysis of the application of pcm and low emissivity coating in hollow bricks." Energy and Buildings 51 (2012): 131-142.

[26] Sayyar, Mohammad, Rankothge R. Weerasiri, Parviz Soroushian, and Jue Lu. "Experimental and numerical study of shape-stable phase-change nanocomposite toward energy-efficient building constructions." Energy and buildings 75 (2014): 249-255.

[27] Lachheb, Mohamed, Mustapha Karkri, and Sassi Ben Nasrallah. "Development and thermal characterization of an innovative gypsum-based composite incorporating phase change material as building energy storage system." Energy and Buildings 107 (2015): 93-102.

[28] Evola, G., L. Marletta, and F. Sicurella. "A methodology for investigating the effectiveness of PCM wallboards for summer thermal comfort in buildings." Building and Environment 59 (2013): 517-527.

[29] Castell, Albert, and Mohammed M. Farid. "Experimental validation of a methodology to assess PCM effectiveness in cooling building envelopes passively." Energy and Buildings 81 (2014): 59-71.

[30] Chung, Min Hee, and Jin Chul Park. "Development of PCM cool roof system to control urban heat island considering temperate climatic conditions." Energy and Buildings 116 (2016): 341-348.

[31] Li, Dong, Yumeng Zheng, Changyu Liu, and Guozhong Wu. "Numerical analysis on thermal performance of roof contained PCM of a single residential building." Energy conversion and management 100 (2015): 147-156.

[32] Kośny, Jan, Kaushik Biswas, William Miller, and Scott Kriner. "Field thermal performance of naturally ventilated solar roof with PCM heat sink." Solar Energy 86, no. 9 (2012): 2504-2514.

[33] Kośny, Jan, Ali Fallahi, Nitin Shukla, Elizabeth Kossecka, and Ramin Ahbari. "Thermal load mitigation and passive cooling in residential attics containing PCM-enhanced insulations." Solar Energy 108 (2014): 164-177.

[34] Kong, Xiangfei, Shilei Lu, Yiran Li, Jingyu Huang, and Shangbao Liu. "Numerical study on the thermal performance of building wall and roof incorporating phase change material panel for passive cooling application." Energy and Buildings 81 (2014): 404-415.

[35] Zhou, Guobing, Yongping Yang, and Hong Xu. "Energy performance of a hybrid space-cooling system in an office building using SSPCM thermal storage and night ventilation." Solar Energy 85, no. 3 (2011): 477-485.

[36] Jiao, Feifei, and Peng Xu. "Simulation and feasibility analysis of PCM based passive cooling technique in residential house." Procedia Engineering 121 (2015): 1969-1976. 
[37] Novais, Rui M., G. Ascensão, M. P. Seabra, and J. A. Labrincha. "Lightweight dense/porous PCMceramic tiles for indoor temperature control." Energy and buildings 108 (2015): 205-214.

[38] Xiang, Yutong, and Guobing Zhou. "Thermal performance of a window-based cooling unit using phase change materials combined with night ventilation." Energy and Buildings 108 (2015): 267-278.

[39] Osterman, Eneja, Vincenc Butala, and Uroš Stritih. "PCM thermal storage system for 'free'heating and cooling of buildings." Energy and buildings 106 (2015): 125-133.

[40] Mosaffa, A. H., L. Garousi Farshi, CA Infante Ferreira, and M. A. Rosen. "Energy and exergy evaluation of a multiple-PCM thermal storage unit for free cooling applications." Renewable Energy 68 (2014): 452-458.

[41] Mosaffa, A. H., CA Infante Ferreira, F. Talati, and M. A. Rosen. "Thermal performance of a multiple PCM thermal storage unit for free cooling." Energy Conversion and Management 67 (2013): 1-7.

[42] Navarro, Lidia, Alvaro de Gracia, Albert Castell, and Luisa F. Cabeza. "Experimental evaluation of a concrete core slab with phase change materials for cooling purposes." Energy and Buildings 116 (2016): 411-419.

[43] Sun, Xiaoqin, Quan Zhang, Mario A. Medina, and Shuguang Liao. "Performance of a free-air cooling system for telecommunications base stations using phase change materials (PCMs): in-situ tests." Applied Energy 147 (2015): 325-334.

[44] Raj, V. Antony Aroul, and R. Velraj. "Heat transfer and pressure drop studies on a PCM-heat exchanger module for free cooling applications." International Journal of Thermal Sciences 50, no. 8 (2011): 1573-1582.

[45] Sun, Xiaoqin, Quan Zhang, Mario A. Medina, Yingjun Liu, and Shuguang Liao. "A study on the use of phase change materials (PCMs) in combination with a natural cold source for space cooling in telecommunications base stations (TBSs) in China." Applied Energy 117 (2014): 95-103.

[46] Tyagi, V. V., A. K. Pandey, D. Buddhi, and S. K. Tyagi. "Exergy and energy analyses of two different types of PCM based thermal management systems for space air conditioning applications." Energy conversion and management 69 (2013): 1-8.

[47] Hasse, Colas, Manuel Grenet, André Bontemps, Rémy Dendievel, and Hébert Sallée. "Realization, test and modelling of honeycomb wallboards containing a Phase Change Material." Energy and Buildings 43, no. 1 (2011): 232-238.

[48] Jaber, Samar, and Salman Ajib. "Novel cooling unit using PCM for residential application." international journal of refrigeration 35, no. 5 (2012): 1292-1303.

[49] Zamfirescu, C., and A. Bejan. "Tree-shaped structures for cold storage." International journal of refrigeration 28 , no. 2 (2005): 231-241.

[50] Tay, N. H. S., M. Belusko, and F. Bruno. "An effectiveness-NTU technique for characterising tubein-tank phase change thermal energy storage systems." Applied Energy 91, no. 1 (2012): 309-319.

[51] Oró, Eduard, Laia Miro, Mohammed M. Farid, and Luisa F. Cabeza. "Thermal analysis of a low temperature storage unit using phase change materials without refrigeration system." International journal of refrigeration 35, no. 6 (2012): 1709-1714.

[52] Liu, Ming, Wasim Saman, and Frank Bruno. "Development of a novel refrigeration system for refrigerated trucks incorporating phase change material." Applied Energy 92 (2012): 336-342.

[53] Liu, Ming, Frank Bruno, and Wasim Saman. "Thermal performance analysis of a flat slab phase change thermal storage unit with liquid-based heat transfer fluid for cooling applications." Solar Energy 85, no. 11 (2011): 3017-3027.

[54] Bruno, Frank, N. H. S. Tay, and M. Belusko. "Minimising energy usage for domestic cooling with off-peak PCM storage." Energy and buildings 76 (2014): 347-353.

[55] Li, Xiao-Yan, Qiao-Qiao Zhao, and Dong-Qi Qu. "Investigation on the dynamic characteristics of a direct contact thermal energy storage charging process for use in conventional air-conditioning systems." Applied Thermal Engineering 91 (2015): 172-180.

[56] Moreno, Pere, Albert Castell, Cristian Sole, Gabriel Zsembinszki, and Luisa F. Cabeza. "PCM thermal energy storage tanks in heat pump system for space cooling." Energy and buildings 82 (2014): 399-405.

[57] Chen, Xiangjie, Mark Worall, Siddig Omer, Yuehong Su, and Saffa Riffat. "Experimental investigation on PCM cold storage integrated with ejector cooling system." Applied Thermal Engineering 63, no. 1 (2014): 419-427. 
[58] Zhai, X. Q., X. W. Cheng, C. Wang, and R. Z. Wang. "Experimental investigation and performance analysis of a fin tube phase change cold storage unit for high temperature cooling application." Energy and Buildings 89 (2015): 9-17. 